doi: $10.15407 /$ ujpe62.07.0583

H.J. ABD, ${ }^{1}$ M.S. ALMAHANNA ${ }^{2}$

${ }^{1}$ University of Babylon, College of Engineering, Department of Electrical Engineering

(Babylon,Iraq; e-mail: haiderlaser@yahoo.com,Eng.haider.jabber@uobabylon.edu.iq)

${ }^{2}$ University of Information Technology and Communication

(Baghdad, Iraq; e-mail: mehdisaleh2004@yahoo.com)

\title{
SUPPRESSION OF A NONLINEAR EFFECT FOR HIGH DATA TRANSNISSION RATE SYSTEMS WITH A WAVELENGTH DIVISION MULTIPLEXER USING THE OPTIMIZATION OF FIBER PROPERTIES
}

\begin{abstract}
The nonlinear crosstalk has a detrimental impact on the efficiency of optical communication systems. It becomes stronger with increasing the data transmission rate and transmission distances. We have investigated and estimated the behavior of a nonlinear effect such as the four wave mixing (FWM) under varying the fiber properties such as the frequency channel spacing, fiber cross-section area, and dispersion. In addition, the demeanour of FWM is observed with the use of two types of an advanced modulation format: Return-to-Zero-Frequency Shift Keying (RZ-FSK) and Non Return-to-Zero Frequency Shift Keying (NRZ-FSK). It is found that the $F W M$ power obtained, when the frequency channel spacing is $80 \mathrm{GHz}$, is drastically reduced to $-77 d B m$ in the RZ-FSK scheme, i.e., a reduction ratio in FWM is more than 21\%. The simulation also shows that the RZ-FSK modulation format under the channel spacing impact offers a better bit error rate (BER) than NRZ-FSK in modern optical communication systems.

Ke ywords: nonlinear effect, four wave mixing, bit error rate, frequency modulation format.
\end{abstract}

\section{Introduction}

More recently, one of the most important obstacles that impede the process of communication through optical fibers is the nonlinear phenomena [1-2]. FWM is the strongest type of this phenomenon, which is considered to render the highest effect on optical signals. It appears, when several optical channels propagate together at the same polarization via the optical fiber [3-5]. To overcome the FWM defect, different approaches and solutions have been investigated [6-12]. The modulation techniques have been reviewed to enhance the robustness of the optical signal to nonlinear effects, which occur inside the fiber [6-9]. The modulation format is suggested for high-speed transmission systems. Nevertheless,

(C) H.J. ABD, M.S. ALMAHANNA, 2017

ISSN 2071-0194. Ukr. J. Phys. 2017. Vol. 62, No. 7 the most advanced modulation format systems are costly.

Kaler et al. [10] made a numerical simulation to calculate the effect of FWM. It was suggested that the FWM could be reduced by managing the dispersion of a fiber. It was proved that the FWM power was reduced, when the dispersion is increased. However, the main drawback of this approach is that no quantitative calculation was obtained for the dispersion map that can suppress the effect of chromatic dispersion. Bassem et al. [11] studied the combined effect of the unequal channel spacing and the duo binary modulation format on the FWM power and compared it with the conventional NRZ modulation at the 10-Gbps data rate. The results show that the duo binary modulation format has a better performance for reducing the FWM effect than NRZ modulation 
and that with the use of an unequal channel spacing with the duo binary format. The drawback of this approach is that no calculation of the FWM reduction effect on the system performance in terms of the bit error rate was made. Shao et al. [12] proposed a new optical modulation transmitter that can transmit an RZ-FSK signal with 40 Gbps. By setting the frequency tone spacing (FTS) of two beams with two values of $100-\mathrm{GHz}$ and $60-\mathrm{GHz}$, the receiver sensitivity is enhanced, where the power penalties after the transmission over $(80) \mathrm{km}$ is $(0.58)$ and $(0.46) \mathrm{dB}$, respectively. The weakness of this technique is in that the effect of the modulation format tolerance toward the nonlinear effect (FWM) was not studied.

However, only a few works, where the effect of the frequency modulation format on the FWM power under varying parameters and a high data transmission rate was studied, are available. This paper has modified and extended work [12]. The FWM power will be calculated under three-parameter variation tunings, by using Optisystem ${ }^{\mathrm{TM}}$ simulation.

\section{System Simulation Design and Parameters}

This section describes the design of a transmitter and a receiver of NRZ-FSK and RZ-FSK as, respectively, shown in Figs. 1 and 2 [12]. The transmitter consists of two external CW laser sources with optical power that is around $(5 \mathrm{dBm})$. The optical line width of laser sources is $10 \mathrm{MHz}$. The two wavelengths are multiplexed into a wavelength division multiplexer (WDM).The external modulator involves of a pseudorandom bit sequence (PRBS), which is connected to a pulse generator named NRZ and then to a MachZehnder modulator (MZM1), which acts as an intensity modulator, and a Mach-Zehnder delay interferometer (MZDI), which is imbalanced by introducing a one-bit time delay line. The second (MZM) is conducted to a sinusoidal signal source with a frequency of $40 \mathrm{GHz}$. The communication link uses the hybrid dispersion map to compensate the dispersion effect in the link, which includes two optical fibers with three optical amplifiers (EDFAs) between them. An EDFA amplifier with a gain of $12 \mathrm{~dB}$ and a noise figure of $4 \mathrm{~dB}$ are used in the transmitter to amplify the optical signal. Two types of nonlinear optical fibers are used, namely, a single-mode fiber (SMF) and a dispersion compensation fiber (DCF). The proposed optical system parameters are listed in Table. At the receiver, an optical band pass filter $(\mathrm{OBPF})$ is used to demultiplex the received FSK signal. It is amplified and detected by a PIN photodiode for the direct detection of signals. PIN has a responsive of $0.8 \mathrm{~A} / \mathrm{W}$ and a dark current of $10 \mathrm{nA}$. The electrical subtractor is used to subtract the electrical signal. It is then passed through a low-pass Bessel filter with a 3-dB cut-off frequency of $0.75 \times$ bit rate, with a filter order of 4 . Regenerators are then used to reconstruct the signal that can be conducted directly to the BER analyzer, which is used to generate the graph. The wavelengths of two laser beams are adjusted so that one beam is at the maximum transmission of the MZD1 (changing the azimuth of a polarization controller $(\mathrm{PC})$ of the first input signal to $0{ }^{\circ} \mathrm{C}$ ), while the other at the minimum (changing the azimuth of the second signal to $90{ }^{\circ} \mathrm{C}$ ), the center frequencies of the two beams being $f_{1}$ and $f_{2}$, respectively. The optical field exiting a phase modulator is given by [12]:

$E_{1}(t)=E_{0} e^{\left(J \frac{2 \pi f_{1} T_{b}+\Phi_{1}+\Phi_{2}}{2}\right)} \cos \left(\frac{2 \pi f_{1} T_{b}+\phi}{2}\right)$,
$E_{2}(t)=E_{0} e^{\left(J \frac{2 \pi f_{2} T_{b}+\Phi_{1}+\Phi_{2}}{2}\right)} \cos \left(\frac{2 \pi f_{2} T_{b}+\phi}{2}\right)$,

where $\Phi_{1}$ and $\Phi_{2}$ are the phases of the neighboring bits, and the data information is reflected in the phase difference $\varphi$, by using the fact that

$f_{1}=\frac{m}{T_{b}}, \quad m=0,1,2,3, \ldots, M$,
$f_{2}=f_{1}+\frac{2 n+1}{2 T_{b}}, \quad n=0,1,2,3, \ldots, N$.

The frequency tone spacing (FTS) of the generated FSK signal should be expressed as

$\mathrm{FTS}=\frac{2 n+1}{2 T_{b}}$.

\section{Simulation Results and Discussions}

\subsection{FWM behavior analysis}

A. Effect of frequency channel spacing

As is known, the different spacings of channels reduces the interference among channels; therefore, the FWM effect is reduced as well. A simulation was carried out to compare the effect of varying the channel spacing for RZ-FSK and NRZ-FSK on the FWM power level. It is clear from Fig. 3 that the technique of frequency channel spacing has a significant effect on reducing the FWM in both modulation formats, 


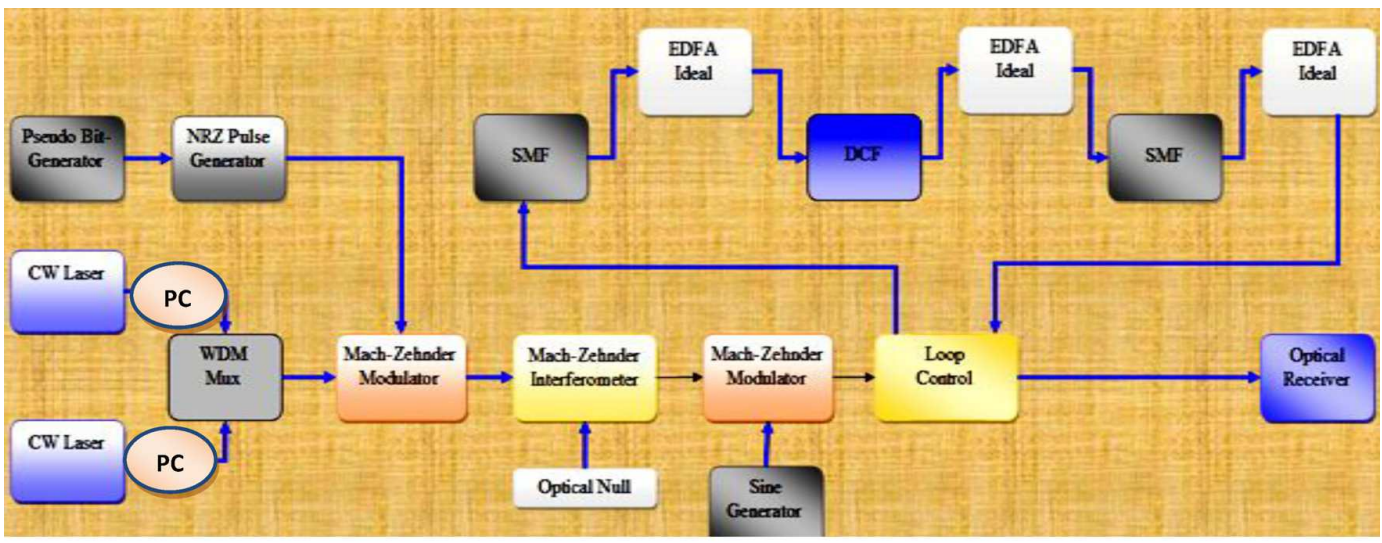

$a$

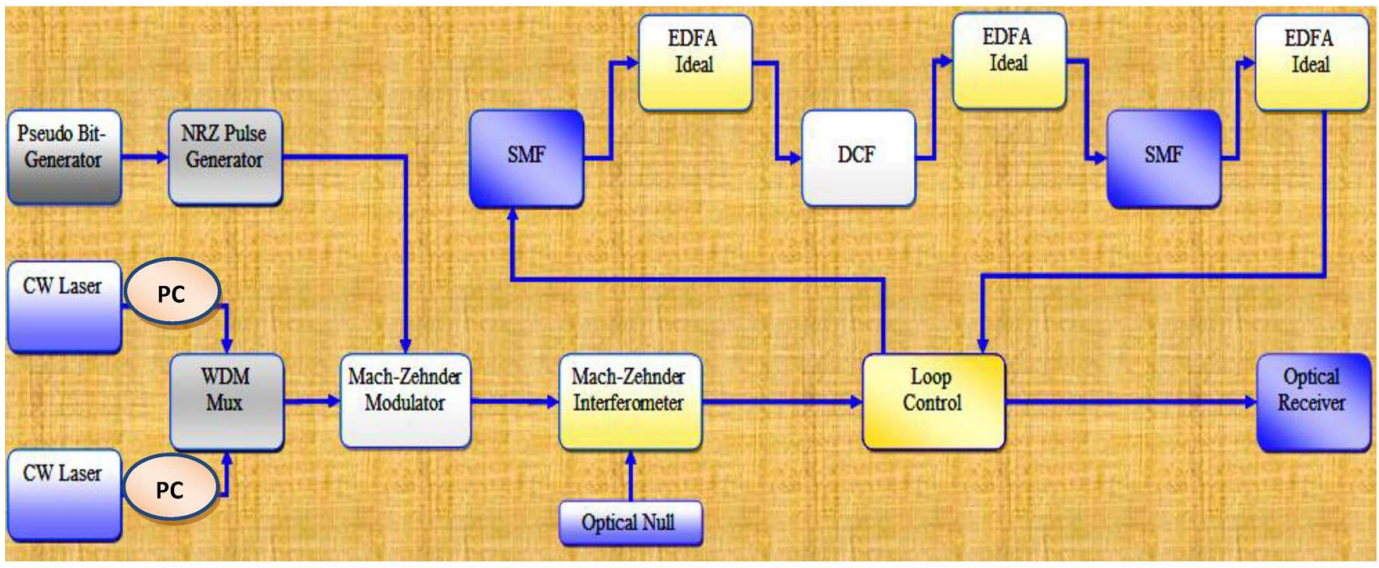

$b$

Fig. 1. System design parameter of a transmitter, RZ-FSK $(a)$; NRZ-FSK $(b)$

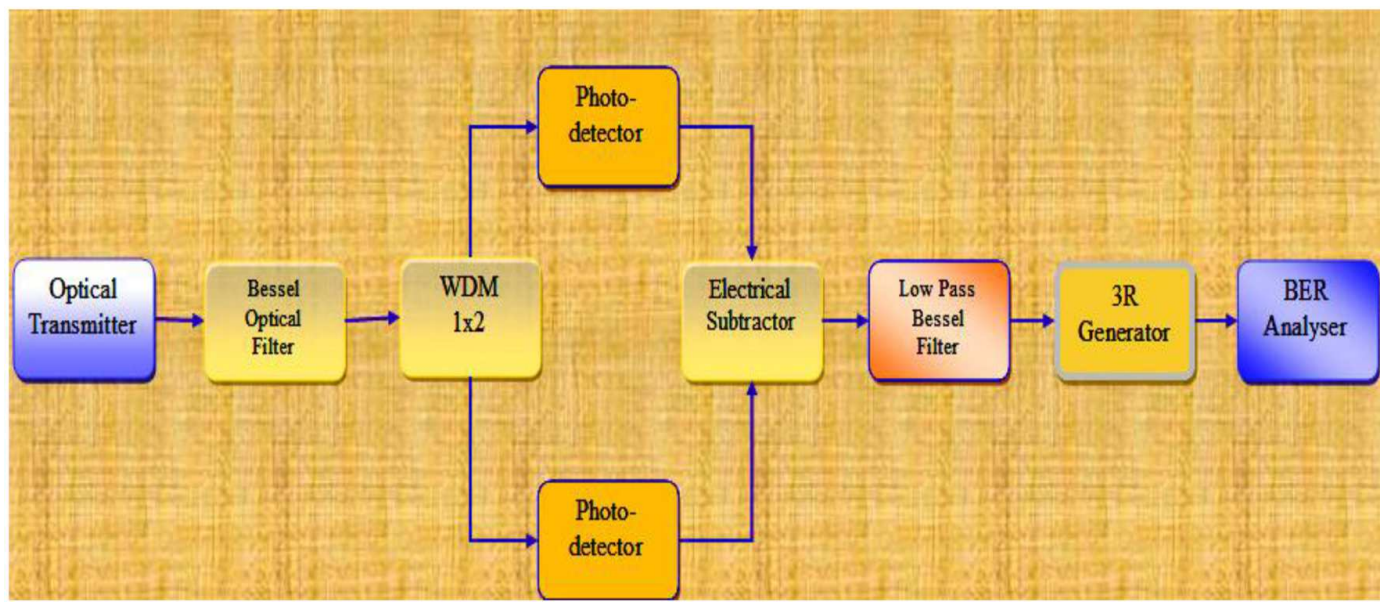

Fig. 2. System design parameter of a receiver of RZ-FSK and NRZ-FSK 


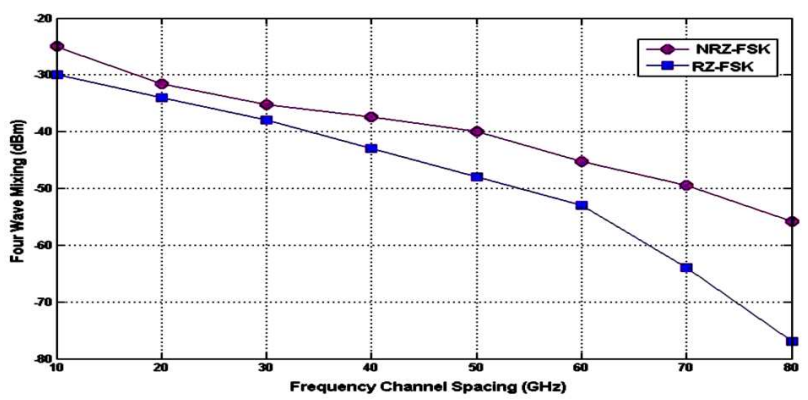

Fig. 3. FWM versus the frequency channel spacing at different modulation formats

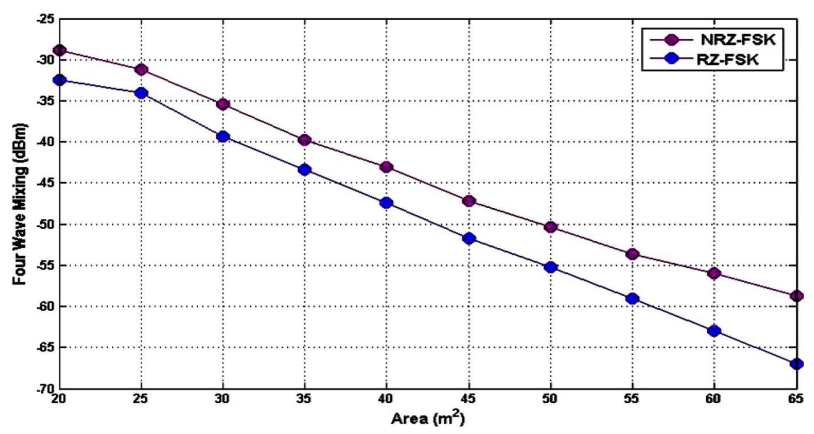

Fig. 4. FWM versus the effective area at different modulation formats

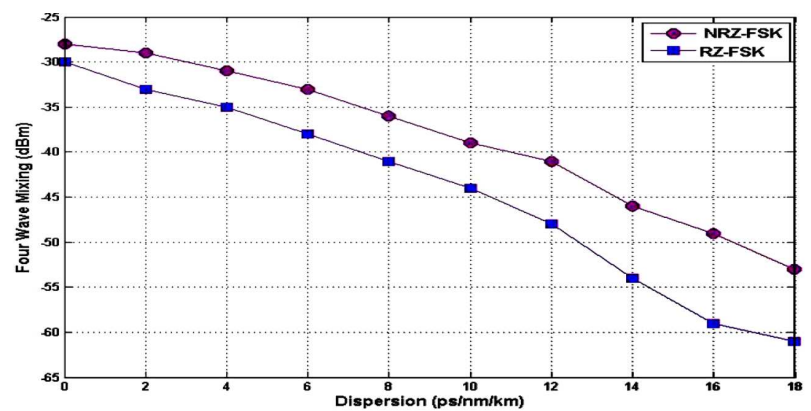

Fig. 5. FWM versus the dispersion at different modulation formats

because an increment in the spacing reduces the probability of the inference between the FWM frequencies. It is observed that the RZ-FSK modulation format is more responsive than NRZ-FSK in terms of the FWM reduction. As can be seen, at the $80-\mathrm{GHz}$ channel spacing, the FWM power is higher in NRZ-FSK $(-55.78 \mathrm{dBm})$ as compared to RZ-FSK $(-77 \mathrm{dBm})$.

\section{B. Effect of cross-sectional area $A\left(\mu m^{2}\right)$}

The cross-sectional area of an optical fiber is an important factor that can be used to increase or decrease

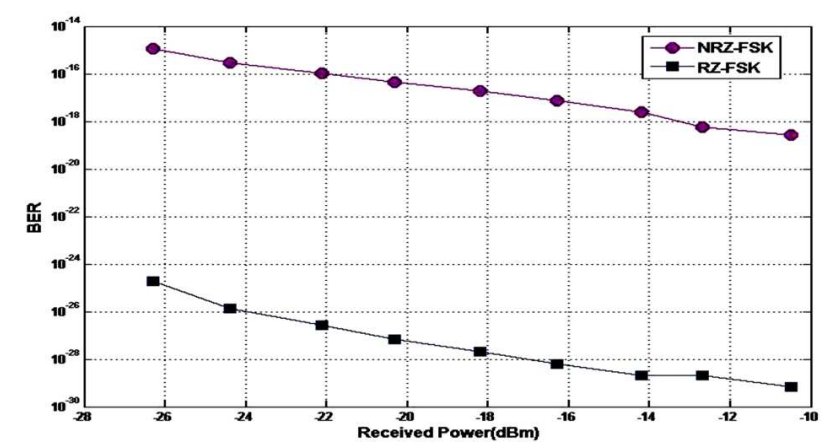

Fig. 6. BER versus the received power for different modulation types

the FWM effect. The FWM power increases with the pump power in the fiber, and the power is inversely proportional to the effective area of the fiber.

Furthermore, when the effective area of the fiber increases, there will be no uniform distribution within the cross-section of the fiber. As shown in Fig. 4, by increasing the effective area of the fiber, the FWM effects will be decreased. The behavior of FWM follows the same trend for RZ-FSK as NRZFSK. However, RZ-FSK performs $5-15 \%$ better, than NRZ-FSK. The FWM has a lower value in RZ-FSK, $67 \mathrm{dBm}$ at the $65-\mu \mathrm{m}^{2}$ effective area, while NRZ-FSK achieves $-58.7 \mathrm{dBm}$ for the same effective area. This finding shows that the RZ-FSK system gave a better performance in reducing the FWM effect as compared to NRZ-FSK.

\section{Effect of dispersion ( $\mathrm{ps} / \mathrm{nm} / \mathrm{km}$ )}

The four wave mixing effect is suspected to be strongly influenced by the chromatic dispersion. The pres-

System design parameter [12-15]

\begin{tabular}{|l|c|c|}
\hline \multicolumn{1}{|c|}{ Parameter } & Unit & Values \\
\hline Fiber length, $L$ & $\mathrm{~km}$ & 60 \\
Input power, $P_{i}$ & $\mathrm{dBm}$ & 5 \\
Channel spacing, $\Delta f$ & $\mathrm{GHz}$ & 10 to 80 \\
Dispersion & $\mathrm{ps} / \mathrm{nm} \cdot \mathrm{km}$ & 0 to 18 \\
Cross effective area, $A_{\mathrm{eff}}$ & $\mu \mathrm{m}^{2}$ & $20-65$ \\
Amplifier gain, $G$ & $\mathrm{~dB}$ & 12 \\
Noise figure & $\mathrm{dB}$ & 4 \\
Factor of attenuation, $\alpha$ & $\mathrm{dB} / \mathrm{km}$ & 0.2 \\
User number & & 2 \\
Data rate & $\mathrm{Gbps}$ & 100 \\
\hline
\end{tabular}

ISSN 2071-0194. Ukr. J. Phys. 2017. Vol. 62, No. 7 

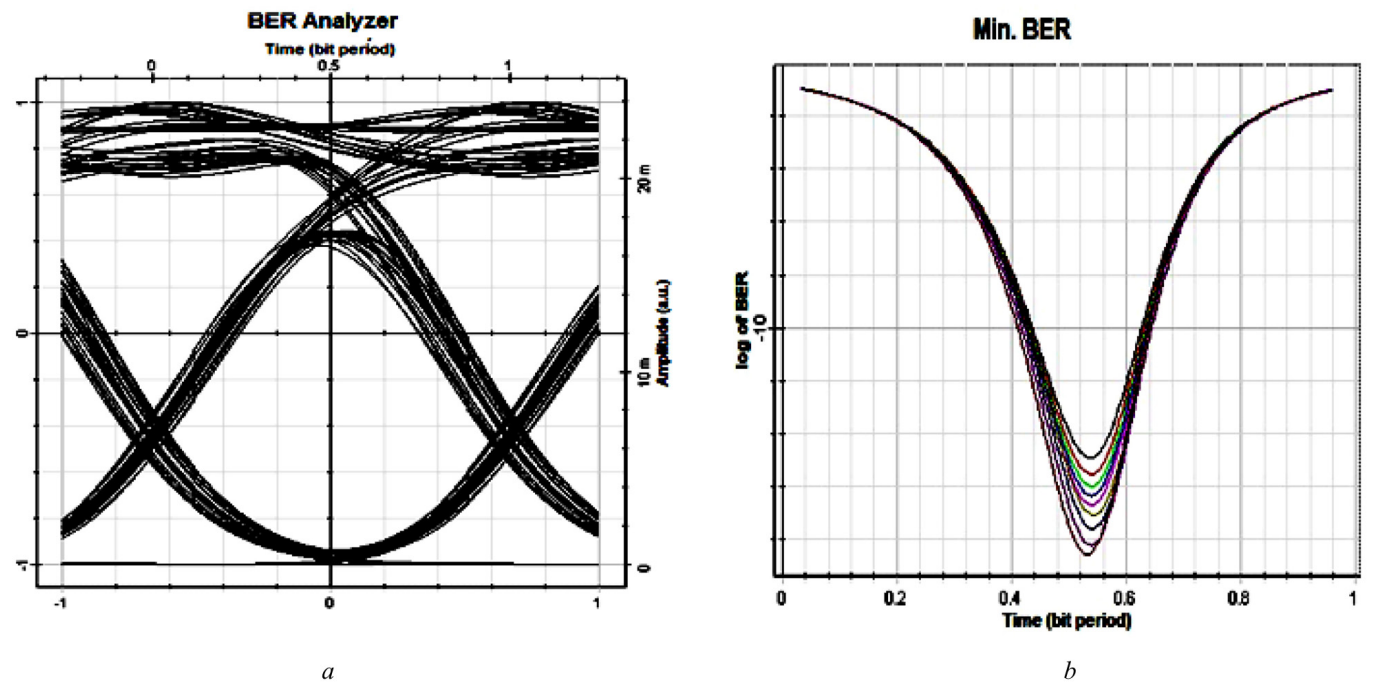

Fig. 7. System performance plotting for NRZ-FSK: Eye diagram $(a)$, BER pattern $(b)$
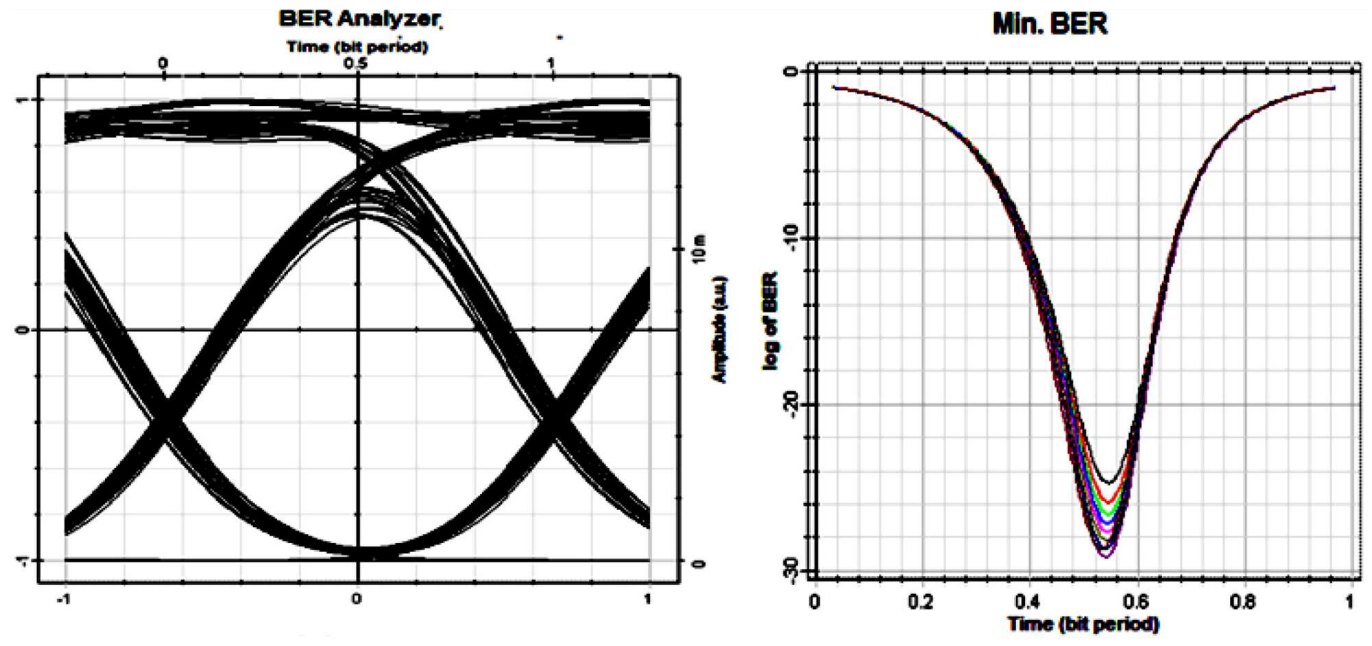

$b$

Fig. 8. System performance plotting for RZ-FSK: Eye diagram (a), BER pattern $(b)$

ence of the chromatic dispersion allows the different signals to travel with different group velocities. Therefore, the different waves will overlap alternately inside, as well as outside, the phase, and the total net effect will decrease the efficiency of mixing. Figure 5 depicts that increasing the dispersion can decrease the FWM for approximately both of modulation formats, NRZ-FSK and RZ-FSK. At the $18-\mathrm{ps} / \mathrm{nm} / \mathrm{km}$ dispersion, the FWM has a higher value of $-53 \mathrm{dBm}$ in the NRZ-FSK modulation format as compared to $-61 \mathrm{dbm}$ for RZ-FSK.

\subsection{System performance analysis}

In this case, the effect of the channel spacing tuning on the system performance in terms of the bit-errorrate was performed with a given modulation. In the case of NRZ-FSK, as is observed in Fig. 6, the increased received power will reduce the BER for all types of modulation implemented. The behavior of BER differed from one modulation to another one, by depending on the property of each type. In the case of RZ-FSK, the system performance gives the minimum value for $\mathrm{BER}$, and it is $6.7 \times 10^{-30}$ at a re- 
ceived power of $-10.5 \mathrm{dBm}$. Conversely, in NRZ-FSK, it gives the value of BER in the range of $\left(6.7 \times 10^{-19}\right)$ at the same received power. In Figs. 7 and 8, the Eye diagram and BER pattern are given. As can be seen, RZ-FSK has a higher Eye diagram than NRZ-FSK and also in BER pattern. The enhance in the system quality in the case of RZ-FSK reflects the robustance of this modulation to the nonlinear effect as compared to NRZ-FSK.

\section{Conclusion}

In this paper, a simulation is proposed to compare the robustness of the two types of modulation formats, RZ-FSK and NRZ-FSK, against the FWM effect. The current simulation is carried out to show the performance of FWM under the variations of different properties, namely, the frequency channel spacing, fiber cross-section area, and dispersion. The findings show that the FWM power level is lowered in RZFSK for all simulated properties. Moreover, RZ-FSK introduces a lowered BER via the optical system simulation. Over all, the channel spacing technique with the $80-\mathrm{GHz}$ spacing with the use of RZ-FSK has reduced the FWM power level to $-77 \mathrm{dBm}$, i.e., has brought a reduction ratio for more than $21 \%$.

1. F. Washman, et. al. Analysis of the four wave mixing effect (FWM) in a dispersion decreasing fiber (DDF) for a WDM system. Optic Fiber Technology 11, 306 (2005).

2. H.J. Abd, M.H. Al-Mansoori, N.M. Din, F. Abdullah, H.A. Fadhil. Priority-based parameter optimization strategy for reducing the effects of four-wave mixing on WDM system. Optik 125, 25 (2014).

3. H.J. Abed, N.M. Din, M.H. AL-Mansoori, H.A Fadhil, F. Abdullah. Recent four-wave mixing suppression methods. Optik 124, 2214 (2013).

4. H.J. Abed, N.M. Din, M.H. Al-Mansoori, F. Abdullah, H.A. Fadhil. A new FWM reduction technique based on damping selective wavelengths. Ukr. J. Phys. 58(10), 956 (2013).

5. H. Abd, N.M. Din, M.H. Al-Mansoori, F. Abdullah, H.A. Fadhil. Four-wave mixing crosstalk suppression based on the pairing combinations of differently linear-polarized optical signals. Sci. World J. 2014, Article ID 243795, 1 (2014).

6. N. Chi, J. Zhang, P.V. Holm-Nielsen, L. Xu, I.T. Monroy, C. Peucheret, K. Yvind, L.J. Christiansen, P. Jeppesen. Experimental demonstration of cascaded transmission and all-optical label swapping of orthogonal IM/FSK labelled signal. Electron. Lett. 39, 676 (2003).

7. Chris u, X. Liu, L.F. Mollenauer, X. Wei. Comparison of return-to-zero differential phase-shift keying and onoff keying in long-haul dispersion managed transmission. IEEE Photon. Techn. Lett. 15, 617 (2003).
8. Y. Han, G.F. Li. Theoretical sensitivity of direct-detection multilevel modulation formats for high spectral efficiency optical communications. IEEE J. Sel. Topics Quantum Electron. 12, 115 (2006).

9. Y. Shao, et. al. A staggered differential phase-shift keying modulation format for $100 \mathrm{Gbit} / \mathrm{s}$ applications. Opt. Exp. 16, 12937 (2008).

10. R.S. Kaler, A.K. Sharma, T.S. Kamal. Simulation results for four wave mixing in an optical fiber near zero dispersion wavelength. J. Electron. Technol. 85, 31 (2004).

11. Bassem. ElRazak, M. Saleh, M. Aly. Duo binary modulation format and unequal channel spacing integration to suppress four-wave mixing crosstalk in WDM systems. in Electronics, Communications and Photonics Conference (SIECPC) 2011 Saudi International, pp. 1-5, IEEE, 2011.

12. Y. Shao, N. Chi, C. Hou, W. Fang, J. Zhang, Bo. Huang, X. Li, S. Zou, X. Liu, X. Zheng, N. Zhang, Y. Fang, J. Zhu, L.Tao, D. Huang. A Novel Return-to-Zero FSK Format for 40-Gb/s Transmission System Applications. J. Lightw. Technol. 28, 1770 (2010).

13. H.J. Abd, M.H. Al-Mansoori, N.M. Din, F. Abdullah, H.A. Fadhil, Four-wave mixing reduction technique based on smart filter approach. Inter. J. Electronics 102 (6), 1056 (2015).

14. H.J. Abd, N.M. Din, M.H. Al-Mansoori, F. Abdullah, H.A. Fadhil. Mitigation of FWM crosstalk in WDM system using polarization interleaving technique Photonics (ICP). IEEE 4th International Conference, 117 (2013).

15. H.J. Abed, N.M. Din, M.H. Al-Mansoori, F. Abdullah, H.A. Fadhil. Comparison among different types of advanced modulation formats under four wave mixing effects. Ukr. J. Phys. 58, 326 (2013).

Received 14.02.16

Х.Дж. Абд, М.С. Алмаханна

ПРИДУШЕННЯ НЕЛІНІЙНОГО

ЕФЕКТУ ОПТИМІЗАЦЕЮ ВЛАСТИВОСТЕЙ

ВОЛОКОН У СИСТЕМАХ З ВИСОКОЮ

ШВИДКІСТЮ ПЕРЕДАЧІ ДАНИХ

З МОДУЛЯТОРОМ-ДІЛЬНИКОМ ДОВЖИН ХВИЛЬ

$\mathrm{P}$ е $з$ ю м е

Нелінійне перехресне накладення погано впливає на ефективність оптичних систем зв'язку. Ефект посилюється зі зростанням швидкості і відстані, на яке передаються дані. Ми досліджуємо такий нелінійний ефект, як чотирихвильове змішування (ЧХЗ) при зміні таких властивостей волокон: відстань між частотними каналами, площа перетину волокна і дисперсія. Крім того, поведінку ЧХЗ вивчено з використанням двох форматів випереджаючої модуляції: управління частотним зрушенням з (I) і без повернення (II) до нуля. Знайдено, що потужність ЧХЗ при відстані між частотними каналами 80 ГГц сильно зменшується на 77 дБм у схемі I, тобто, коефіцієнт зменшення ЧХЗ більший, ніж $21 \%$. Моделювання показало, що формат модуляції I при впливі рознесення каналів дає меншу інтенсивність помилок, ніж формат II для сучасних оптичних систем зв'язку. 